\title{
Review of esophageal metastasis from breast cancer
}

\author{
Hui Su${ }^{1,2}$, Jing $\mathrm{Wu}^{2}$, Hong $\mathrm{Liu}^{2}, \mathrm{Nan} \mathrm{Wei}^{2}, \mathrm{Wu} \mathrm{Lin}^{2}$, Quan Zhou ${ }^{3}$, Miaomiao Wang ${ }^{2}$, Shuzhen $\mathrm{Lv}^{4}$, \\ Yunsheng Yang ${ }^{1}$
}

${ }^{1}$ Department of Gastroenterology and Hepatology, Chinese PLA General Hospital, Medical School of Chinese PLA, Beijing 100853, China; ${ }^{2}$ Department of Gastroenterology, Capital Medical University Affiliated Beijing Shijitan Hospital, Beijing 100038, China; ${ }^{3}$ Department of Pathology, Capital Medical University Affiliated Beijing Shijitan Hospital, Haidian District, Beijing 100038, China; ${ }^{4}$ Department of Breast surgery, Capital Medical University Affiliated Beijing Shijitan Hospital, Beijing 100038, China

Contributions: (I) Conception and design: H Su, Y Yang; (II) Administrative support: J Wu, H Liu; (III) Provision of study materials or patients: H Liu, N Wei, W Lin; (IV) Collection and assembly of data: H Su, Q Zhou, S Lv, M Wang; (V) Data analysis and interpretation: H Su, M Wang; (VI) Manuscript writing: All authors; (VII) Final approval of manuscript: All authors.

Correspondence to: Yunsheng Yang. Department of Gastroenterology and Hepatology, Chinese PLA General Hospital, Medical School of Chinese PLA. No. 28, Fuxing Road, Haidian District, Beijing 100853, China. Email: yangyunshengy126@126.com.

\begin{abstract}
Esophageal metastasis of primary breast cancer is rare, with nearly all the literature on this topic consisting of case report studies. When breast cancer patients complain of progressive dysphagia after a long disease-free interval after breast surgery, they may be treated and misdiagnosed with a second primary. Our aim was to review all the literature concerning esophageal metastasis of breast cancer, for the purpose of improving the awareness in identifying these patients and providing them proper treatment.
\end{abstract}

Keywords: Esophageal metastasis; breast cancer; esophageal stricture

Submitted Feb 24, 2020. Accepted for publication Mar 30, 2020.

doi: $10.21037 /$ gs.2020.04.05

View this article at: http://dx.doi.org/10.21037/gs.2020.04.05

\section{Background}

The esophagus is an unusual metastatic site of primary breast cancer, and the relevant literature is almost exclusively from case reports. Since 1989, a total of 25 case reports, comprising 65 cases, including our case of esophageal metastasis from breast cancer, were published in the English language. Some of these have had been previously summarized by Wada et al. (1) and Miyake et al. (2), and the largest series of 25 cases of esophageal metastasis from breast cancer were reported in 2007 by Rampado et al. (3). Another latest case reports was published in Nov 2018 (4). All 65 cases are summarized in Table 1, which shows that fewer than $30 \%$ of patients had a disease-free interval of more than 15 years after breast cancer therapy, and fewer than $10 \%$ of patients had more than 5 years of survival from the diagnosis of esophageal metastasis. The case we encountered was diagnosed with esophageal metastasis from breast cancer 18 years after surgery. The patient had a better quality of life for more than 6 years of post-chemo and hormone therapy. We thus conducted this literature review of esophageal metastasis of breast cancer, with the aim of improving the awareness of identifying these patients and giving them proper treatment.

\section{Epidemiology}

Esophageal metastasis of breast cancer is rarely diagnosed, and the prevalence of esophageal metastasis from breast cancer is $4.2-5.9 \%(5,6)$. However, Borst and Ingold followed 2,246 breast cancer patients for an 18-year period and reported an esophageal metastasis prevalence of only $0.4 \%$ (7). These studies revealed that the prevalence of esophageal metastasis from breast cancer was different between autopsy and clinical observation. The reason for this may be that once patients have esophageal metastasis from breast cancer, they are already in the terminal stage of disease, and if they died of other reasons and had not accepted autopsy, the esophageal metastasis would not be discovered. Because of this, a considerable number 


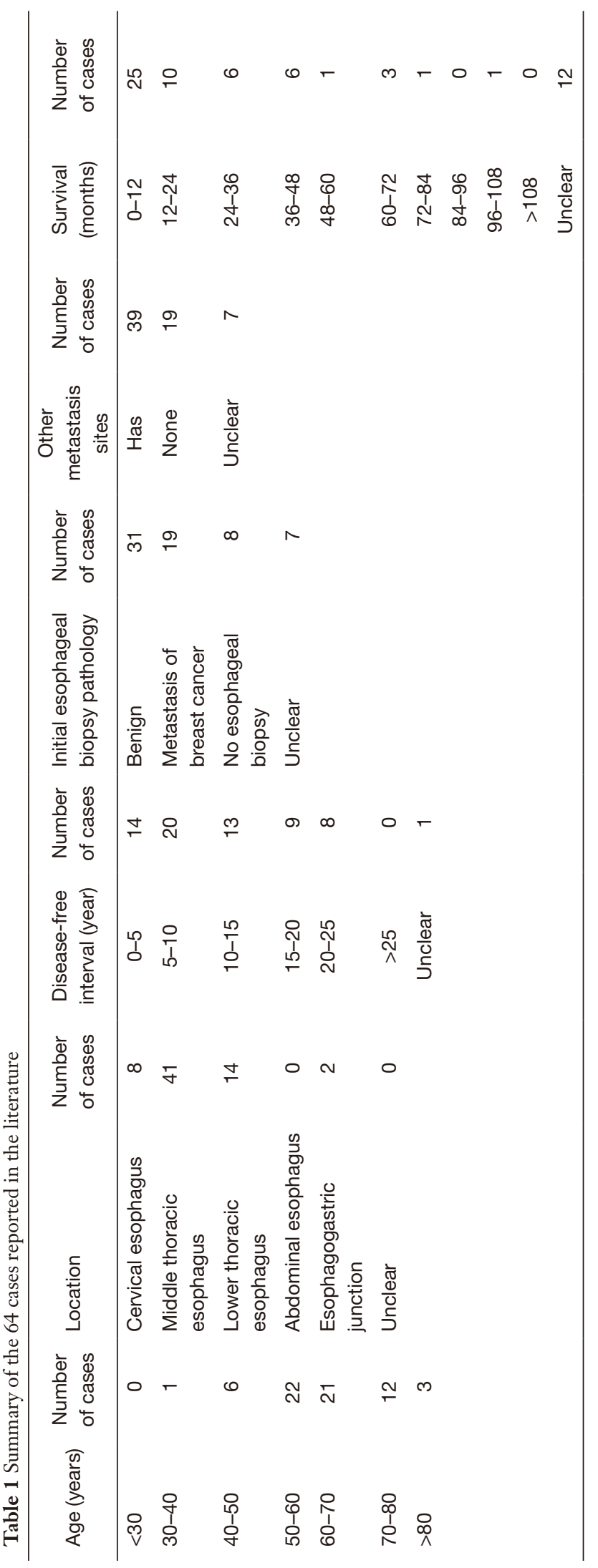

of esophageal metastasis cases would be a clinically underreported. For instance, in Borst and Ingold's study (7), $5.9 \%$ of autopsies of patients revealed breast cancer with esophageal metastasis, but only $0.59 \%$ of the patients complained of dysphagia. Thus, there is not always an opportunity to find esophageal metastasis in the patients without dysphagia.

\section{Clinical manifestation}

For some breast cancer patients in remission or after a long period of breast surgery, esophageal or mediastinal metastases from breast cancer is always initially asymptomatic, but a clinical syndrome may develop after a long disease-free interval (8). The reported disease-free interval was longer than 5 years for $78 \%$ patients (Table 1) who complained of progressive dysphagia and accepted endoscopy or esophagram. These showed esophageal stricture, but with the esophagus being covered by normal mucosa. Because of the involvement of the esophageal wall from the outside inwards, metastasis in the mucosal layers of the esophageal wall is extremely rare (Figure 1). The result of initial biopsy was benign in almost half of the reported cases (Table 1), and these patients might have been mistakenly diagnosed with a benign stricture or a second primary, and treated accordingly. Chest computed tomography (CT) showed a circumferential wall thickening of the esophagus wall, with the lesions being inhomogeneously enhanced (Figure 2). Esophagrams showed the length and degree of esophageal stenosis (Figure 3).

As can be seen in Table 1, metastatic breast cancer to the esophagus most often affected the mid or lower third of the esophagus (3), with more than $80 \%$ of patients metastasizing to the middle or lower thoracic esophagus.

Esophageal metastasis may be the primary metastasis or part of a systemic metastasis of breast cancer. For the cases we reviewed including our case, 39 of 65 cases had distant metastasis, 19 of the 65 cases did not report other metastasis sites, and 7 of the 65 cases were unclear (Table 1).

The mechanism of how breast cancer metastasizes to the esophagus is controversial. The most likely pathway is lymphatic. Lymophogenous metastasis of the paraesophageal lymph nodes occurs via the parasternal lymph and mediastinum, and thus the intramural lymphatics of the esophagus cause the stenosis of the esophagus.

The middle third of the esophagus is the most frequent site of metastasis perhaps because of the involvement of 

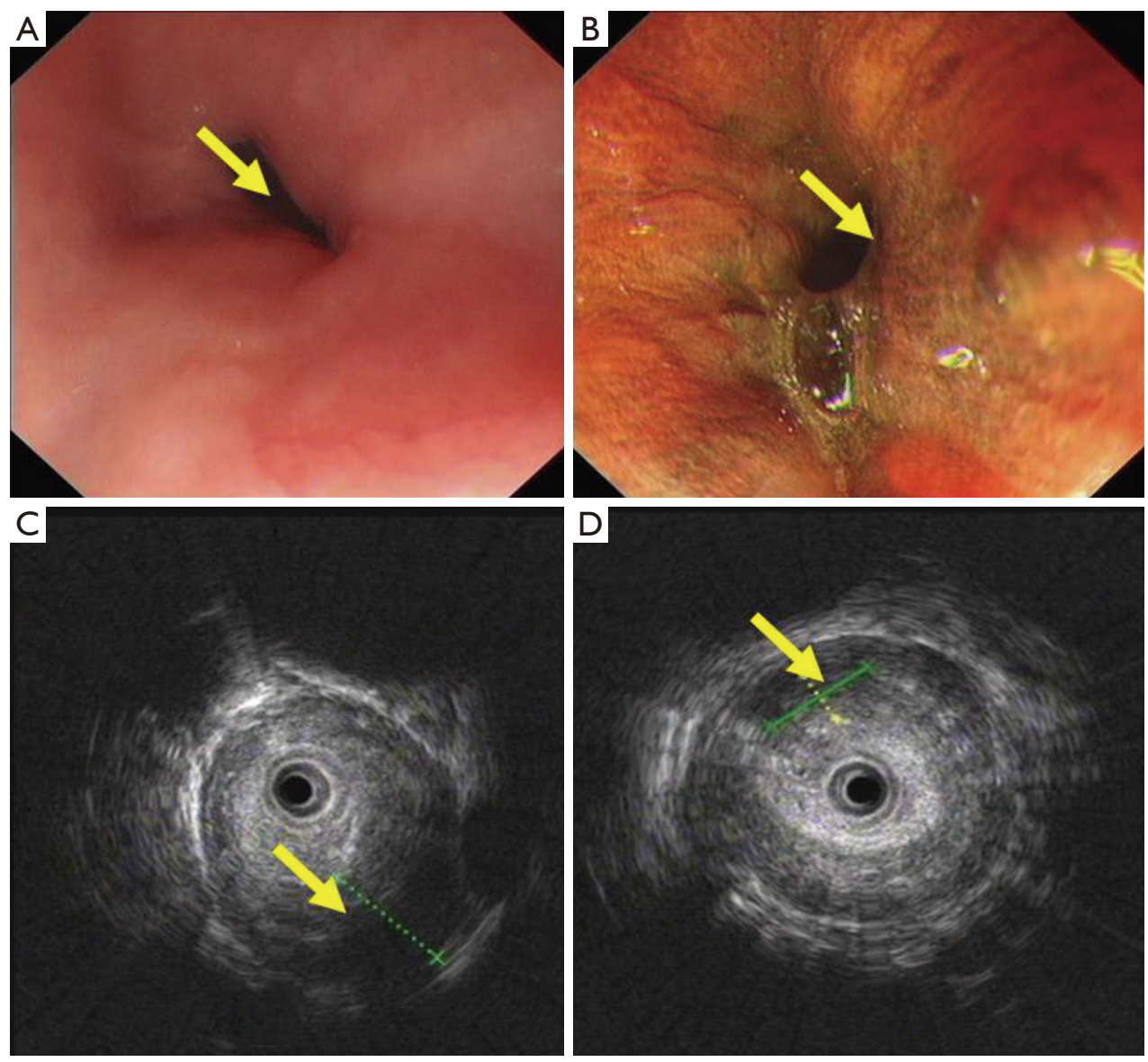

Figure 1 Endoscopy and ultrasound endoscopic examination of our case. (A) HD white light endoscopy showing stricture of the mid esophagus; (B) the lesion stricture was lightly stained by $1.2 \%$ Lugo's iodine; (C,D) 20 M endoscopic ultrasound showing the lesion originating from the intrinsic muscular layer, which was markedly thicker than normal. HD, high definition.

the intertracheobronchial lymph nodes and the lymphatic connections in the mediastinum (9). Consequently, mediastinal localization is more exact than esophageal metastasis in representing this condition. There is another hematogenous metastasis pathway that is present when mediastinal lymph node enlargement is absent.

\section{Diagnosis}

It is difficult to diagnose an esophageal stricture as metastasis from primary breast cancer. Rampado et al. (3) reported that patients with secondary esophageal cancer would experience dysphagia for about 8 months. The diagnosis of esophageal metastasis from breast cancer depends on a clinical history of breast cancer, and imaging examinations, including esophagography, endoscopy, endoscopic ultrasound, and CT scan, could also be helpful.

When breast cancer patients complain of dysphagia, we should be aware not only of esophageal cancer, benign strictures, and esophageal motility diseases, but also metastatic disease. When we found stricture of the esophagus using CT or endoscopy in patients who had a history of breast cancer, endoscopic examination with ultrasonography could help us to confirm the lesion origin (Figure 1). The lesion of esophageal metastasis always originates from the outside inwards, and metastasis to the mucosal layers are extremely rare; thus, from solely referring to a single histopathological examination of mucosal biopsy specimens, we could not make the correct diagnosis for the patients. Endoscopic ultrasound-guided fine-needle aspiration (EUS-FNA) could improve the positive rate of biopsy. Sobel et al. (10) reported that EUS- 

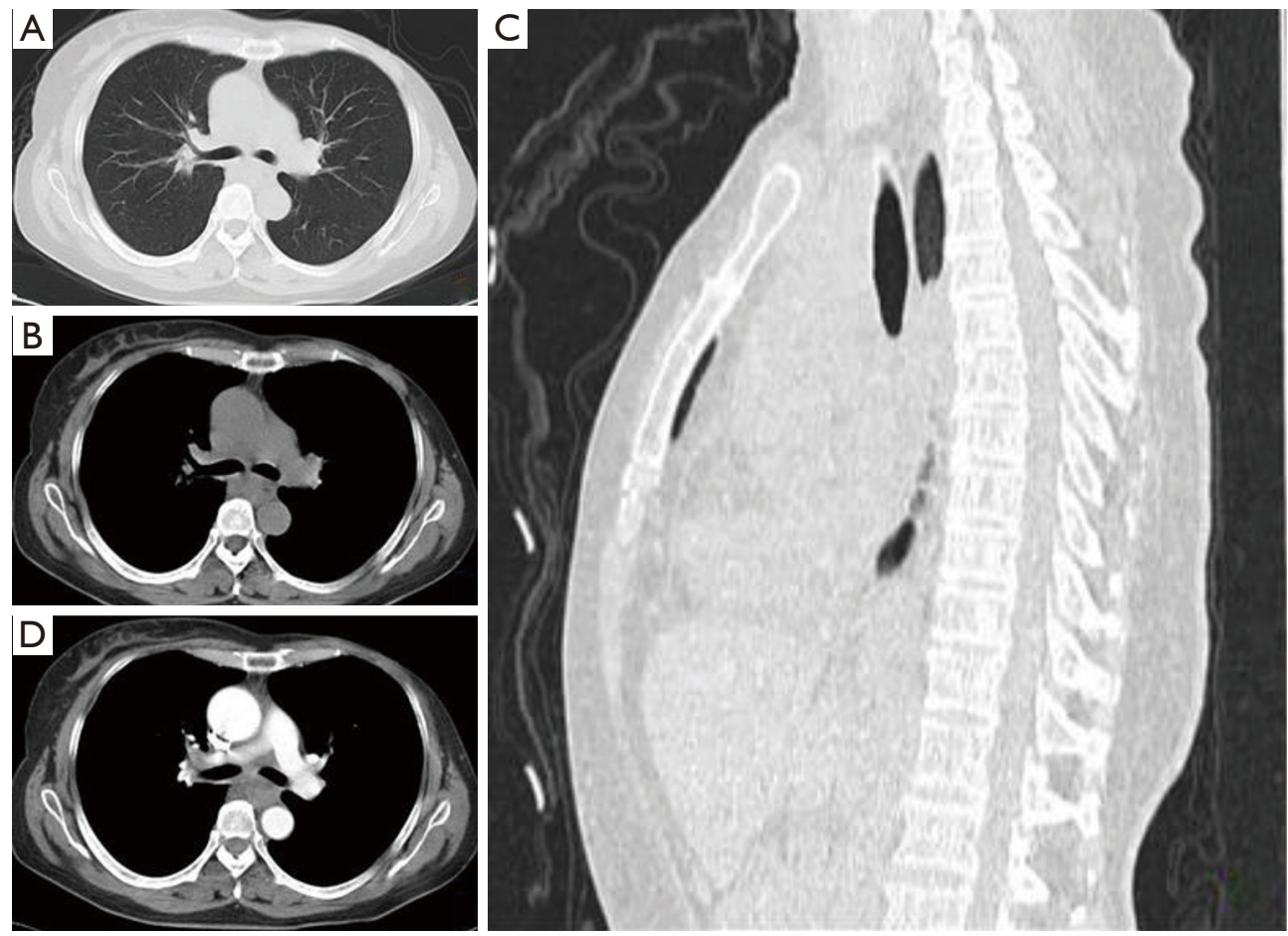

Figure 2 CT scan of our case. (A,B,C) Circumferential wall thickening of the middle esophagus with enlarged lymph nodes around the esophagus; (D) CT scan showing the lesion was inhomogeneously enhanced.

FNA is safe and effective for the diagnosis of esophageal and mediastinum metastasis from breast cancer: 11 of the 12 patients (91\%) were confirmed breast cancer metastasis by cytological evaluation of specimens obtained by EUSFNA, and no complication occurred. Mediastinoscopy or surgery could be available for a definitive diagnosis, but these methods are more invasive than EUS-FNA (11), while esophagography and CT scan could reveal the length and degree of esophageal stenosis and whether there are mediastinal metastases.

For the patients with dysphagia, we should determine whether there are benign or malignant diseases. Dysphagia caused by malignant diseases is often progressive, and imaging examination will exhibit esophageal stricture. We should diagnostically differentiate between primary esophageal tumor,post-radiotherapy stenosis, peptic stricture, and mediastinal carcinomatosis.

Definitive diagnosis should depend on histopathology, as immunohistochemistry can determine the origin of tumor cells and is especially useful for differentiating from initial breast cancer.

\section{Treatment}

Goldberg et al. reported that esophageal metastasis originating from breast cancer often occurred as a part of multiple-organ metastases (12), meaning once the patients have esophageal metastasis from breast cancer, they are already in the terminal stage of disease, and would have a poor prognosis. Treatment should be decided according to the severity of other metastatic sites and on the degree of the esophageal stenosis. Treatment for recurrent breast cancer is generally palliative, so for the patients with esophageal metastasis as part of systemic metastasis, the first-line option for esophageal metastasis of breast cancer is systemic (chemo- and/or endocrine-) therapy in combination with radiotherapy (1). Dilations/prostheses with endoscopy have high related risk of perforation because the tumor tissue is relatively brittle and inelastic. Surgical resection is not recommended for the esophageal metastatic lesions from breast cancer due to the high incidence of multiple metastases, unless the patient only has esophageal metastasis; indeed, one previous case (13) 

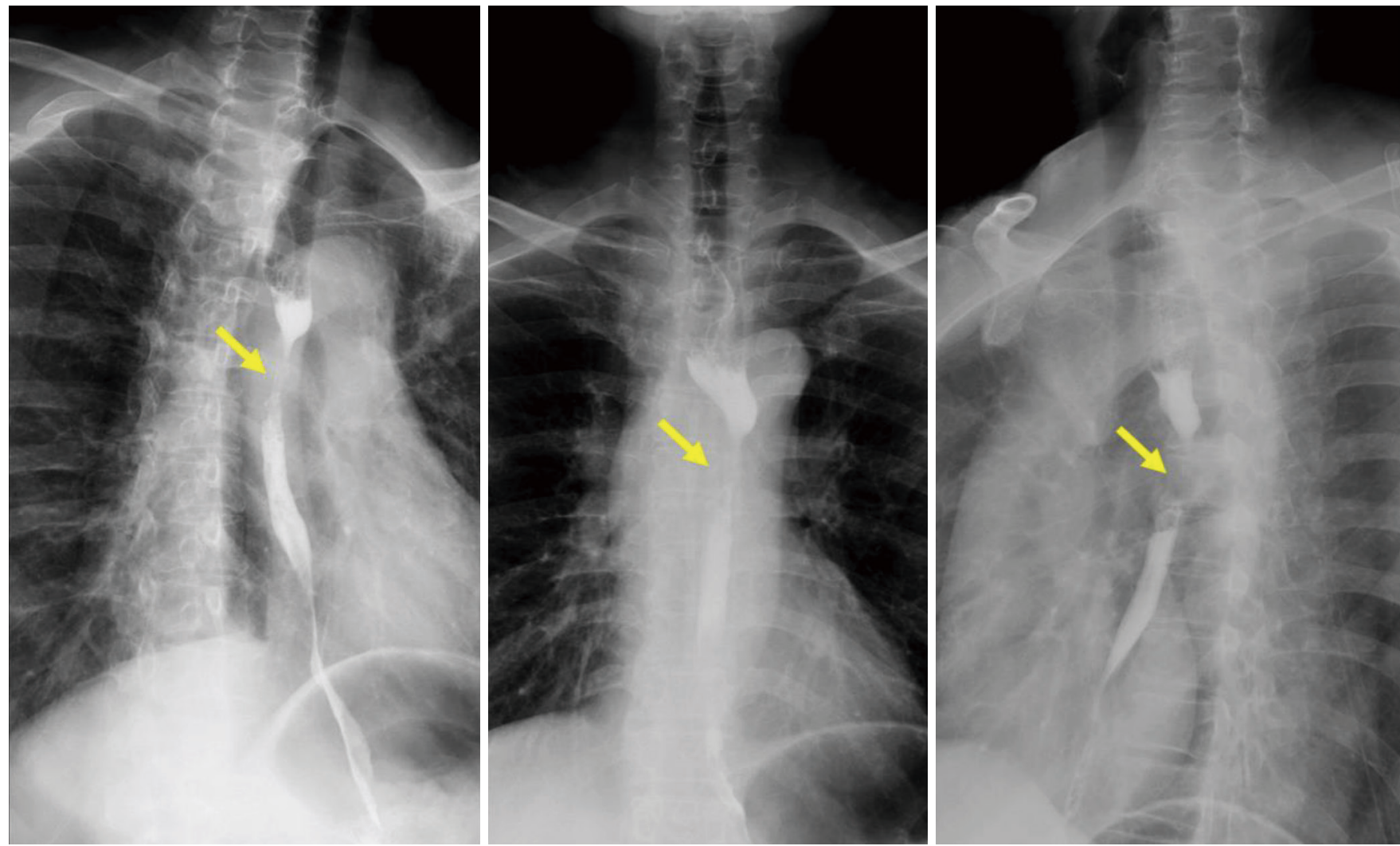

Figure 3 Contrast barium esophagography of our case showing concentric stenosis of the esophagus. The lesion length was $2.7 \mathrm{~cm}$ and the lesion of esophagus was stiff with a clear boundary.

reported an incidental curative resection. Furthermore, a report from Mayo Clinic (14) confirmed that chemotherapy and hormonal therapy could significantly affect survival.

\section{Conclusions}

Though the esophageal involvement from breast cancer is unusual, for the patients with breast cancer history, the possibility of esophageal metastasis should be considered during follow-up examinations to maintain a diseasefree status. Dysphagia could be a symptom of esophageal metastasis. Endoscopic examination with ultrasonography can help us to confirm the lesion origin, and EUS-FNA can improve the positive rate of biopsy. The first-line option for esophageal metastasis of breast cancer is systemic (chemo- and/or endocrine-) therapy in combination with radiotherapy.

\section{Acknowledgments}

The authors would like to thank Vijay Kumar Kolluri (Soochow University Medical College) for language editing.

Funding: None.

\section{Footnote}

Conflicts of Interest: All authors have completed the ICMJE uniform disclosure form (available at http://dx.doi. org/10.21037/gs.2020.04.05). The authors have no conflicts of interest to declare.

Ethical Statement: The authors are accountable for all aspects of the work in ensuring that questions related to the accuracy or integrity of any part of the work are appropriately investigated and resolved. 
Open Access Statement: This is an Open Access article distributed in accordance with the Creative Commons Attribution-NonCommercial-NoDerivs 4.0 International License (CC BY-NC-ND 4.0), which permits the noncommercial replication and distribution of the article with the strict proviso that no changes or edits are made and the original work is properly cited (including links to both the formal publication through the relevant DOI and the license). See: https://creativecommons.org/licenses/by-nc-nd/4.0/.

\section{References}

1. Wada Y, Harada N, Ohara K, et al. Esophageal metastasis of breast carcinoma. Breast Cancer 2009;16:151-6.

2. Miyake M, Yamada A, Miyake K, et al. Esophageal metastasis of breast cancer during endocrine therapy for pleural dissemination 21 years after breast surgery: a case report. Surg Case Rep 2019;5:22.

3. Rampado S, Ruol A, Guido M, et al. Mediastinal carcinosis involving the esophagus in breast cancer: the "breastesophagus" syndrome: report on 25 cases and guidelines for diagnosis and treatment. Ann Surg 2007;246:316-22.

4. Liu A, Feng Y, Chen B, et al. A case report of metastatic breast cancer initially presenting with esophageal dysphagia. Medicine 2018;97:e13184.

5. Fan $\mathrm{W}$, Jiang $\mathrm{H}$, Chen $\mathrm{H}$, et al. Esophageal metastasis from endometrial adenocarcinoma: a case report and literature review. Transl Cancer Res 2018;7:1178-83.

6. Asch MJ, Wiedel PD, Habif DV. Gastrointestinal metastases from crcinoma of the breast. Autopsy study

Cite this article as: $\mathrm{Su} \mathrm{H}, \mathrm{Wu}$ J, Liu H, Wei N, Lin W, Zhou Q, Wang M, Lv S, Yang Y. Review of esophageal metastasis from breast cancer. Gland Surg 2020;9(2):417-422. doi: 10.21037/ gs.2020.04.05 and 18 cases requiring operative intervention. Arch Surg 1968;96:840-3.

7. Borst MJ, Ingold JA. Metastatic patterns of invasive lobular versus invasive ductal carcinoma of the breast. Surgery 1993;114:637-41; discussion 641-2.

8. Graham WP 3rd. Gastro-Intestinal Metastases from Carcinoma of the Breast. Ann Surg 1964;159:477-80.

9. Sanborn EB, Beattie EJ Jr, Slaughter DP. Secondary neoplasms of the mediastinum. J Thorac Surg 1958;35:678-82.

10. Sobel JM, Lai R, Mallery S, et al. The utility of EUSguided FNA in the diagnosis of metastatic breast cancer to the esophagus and the mediastinum. Gastrointest Endosc 2005;61:416-20.

11. Matsumoto Y, Matsukawa H, Seno H, et al. Education and imaging. Gastrointestinal: breast cancer metastasis to the esophagus diagnosed using endoscopic ultrasoundguided fine-needle aspiration. J Gastroenterol Hepatol 2015;30:233.

12. Goldberg RI, Rams H, Stone B, et al. Dysphagia as the presenting symptom of recurrent breast carcinoma. Cancer 1987;60:1085-8.

13. Wilson MA, Shah N, O'Donnell ME, et al. An unusual presentation of esophageal metastasis from breast cancer. J Thorac Cardiovasc Surg 2015;149:e110-2.

14. McLemore EC, Pockaj BA, Reynolds C, et al. Breast cancer: presentation and intervention in women with gastrointestinal metastasis and carcinomatosis. Ann Surg Oncol 2005;12:886-94. 